Ciência Florestal, Santa Maria, v. 24, n. 2, p. 509-519, abr.-jun., 2014

ISSN 0103-9954

\title{
NUCLEAÇÃO: CONCEPÇÃO BIOCÊNTRICA PARA A RESTAURAÇÃO ECOLÓGICA
}

\author{
NUCLEATION: BIOCENTRIC CONCEPTION FOR THE ECOLOGICAL RESTORATION
}

\author{
Ademir Reis ${ }^{1}$ Fernando Campanhã Bechara ${ }^{2}$ Deisy Regina Tres ${ }^{3}$ Bruna Elisa Trentin ${ }^{4}$
}

\begin{abstract}
RESUMO
O conflito homem vs. natureza será uma nova síntese para processos de restauração? Quais modelos e técnicas usam-se para entender e fazer restauração? Quai as implicações que decorrem da escolha de um paradigma para o processo de restauração? Para o desenvolvimento da raça humana sobre o planeta Terra houve a necessidade de drásticas mudanças nas paisagens, estrutura e funcionalidade dos ecossistemas. Técnicas de produtividade foram responsáveis para a manutenção da sociedade, mas no mínimo, não são as adequadas para os processos de restituição da natureza, pois restauração da biodiversidade não é sinônimo de produtividade. Uma nova tendência de restauradores prima por resgatar modelos de conservação da biofuncionalidade e resgate de interações entre organismos do sistema. A nucleação representa uma oportunidade de incorporar os princípios-chave da metáfora do "fluxo da natureza" à prática da restauração ecológica. A proposta do modelo de nucleação é biocêntrica: auxiliar a natureza em núcleos que recobrem em torno de 10 a $30 \%$ da área degradada e permitir que nos demais espaços seja restabelecida uma complexa rede de interações entre os organismos e uma heterogeneidade sucessional, nos quais o ecossistema poderá convergir para múltiplos pontos de equilíbrio no espaço e no tempo.
\end{abstract}

Palavras-chave: facilitação; sucessão; heterogeneidade; áreas degradadas.

\begin{abstract}
Is the conflict of man versus nature a new synthesis for restoration processes? What models do we use to understand and apply restoration? What are the implications resulting from the choice of a paradigm for the restoration process? The development of the human race on Earth required drastic changes in the landscapes, structures and functionalities of the planet's ecosystems. Techniques of productivity were responsible for the maintenance of the society, but those techniques do not serve to restitute nature, because the restoration of biodiversity is not a synonymous of productivity. A new tendency of restorers is to retrieve models of biofunctionality conservation and of interactions among the organisms of the system. Nucleation represents an opportunity to apply the key principles of the metaphor of the "flow of nature" to the practice of ecological restoration. The proposal of the nucleation model is biocentric, namely, to aid nature in nuclei covering about $10-30 \%$ of the degraded area, allowing a complex network of interactions between the organisms and a successional heterogeneity to be reestablished in the remaining space, where the ecosystem can converge towards multiple points of equilibrium in space and time.
\end{abstract}

Keywords: facilitation; succession; heterogeneity; degraded areas.

1 Biólogo, Dr., Professor Titular do Departamento de Botânica da Universidade Federal de Santa Catarina, Campus Universitário, CEP 88040-900, Florianópolis (SC), Brasil. ademir@rasambiental.com.br

2 Engenheiro Florestal, Dr., Professor da Coordenação de Engenharia Florestal da Universidade Tecnológica Federal do Paraná, Campus Universitário, CEP 85660-000, Dois Vizinhos (PR), Brasil. bechara@utfpr.edu.br

3 Bióloga, Dr ${ }^{\mathrm{a}}$., Doutora pelo Programa de Pós Graduação em Recursos Genéticos Vegetais da Universidade Federal de Santa Catarina, Campus Universitário, CEP 88040-900, Florianópolis (SC), Brasil. tres_deisy@yahoo.com.br

4 Graduanda em Engenharia Florestal pela Universidade Tecnológica Federal do Paraná, Campus Universitário, CEP 85660-000, Dois Vizinhos (PR), Brasil. brunaelisatrentin@gmail.com

Recebido para publicação em 10/10/2011 e aceito em 7/01/2013

Ci. Fl., v. 24, n. 2, abr.-jun., 2014 


\section{INTRODUÇÃO}

A atual situação ambiental, na concepção abordada por Ost (1995), por um lado envolve um grande processo de destruição das comunidades naturais que cobrem o planeta Terra, e por outro, aborda o reconhecimento de que o próprio homem tem sua crise de relação com a natureza. Como encarar o posicionamento do homem diante da natureza? Segundo este autor há a necessidade de enquadramento entre as semelhanças e as diferenças da espécie humana com a natureza. O homem como espécie dominante do planeta é privilegiado por uma forte concepção de liberdade, sujeito de uma história, autor e destinatário das regras estabelecidas. A natureza, como produtora de uma evolução que culminou com a evolução desta espécie, tem assegurado as condições de sobrevivência, mas acaba sendo completamente diferente, absolutamente estranha e drasticamente modificada por este processo.

Dansereau (1966) descreveu as atividades humanas e os impactos sobre o meio ambiente (coleta, caça e pesca, pastoreio, agricultura, indústria, urbanização, controle climático) e previu que a solução seria uma exobiologia, ou seja, o homem partindo para um novo planeta na busca de outros recursos.

A atual concepção de meio ambiente e a integração do homem ao mesmo é drástica e exige uma reflexão sobre a sua real postura, principalmente no que diz respeito ao seu papel de reconstituidor da natureza. Os conflitos sociais que esta atitude acarreta são ainda muito vagos, mas representam uma grande esperança. Parafraseando Nietzsche (1995), discutindo a filosofia grega de Heráclito, aspira-se que todo o devir (to come into being) que nasce dos contrários, exprima não somente uma superioridade momentânea, mas que produza uma síntese, uma nova situação, ou seja, uma nova concepção do papel do homem no manejo da natureza produtiva e conservativa sobre o planeta.

No entanto, o atual desenvolvimento começa a mostrar a necessidade de conciliar as áreas produtivas com áreas de conservação de forma a provocar uma sinergia entre estas paisagens drasticamente fragmentadas. Para isto, a restauração de áreas degradadas, principalmente no sentido de aumentar a conectividade entre remanescentes naturais, torna-se uma ação vital para manter a qualidade de vida sobre o planeta Terra.

Parker e Pickett (1999) evidenciam dois problemas básicos que dificultam o nosso entendimento dos processos naturais. $\mathrm{O}$ primeiro é idealizar a natureza; o segundo problema é ver a natureza como fixa e imutável. Ambos os problemas resultam em concepções antropormorfizadas da natureza, que evidenciam aspectos determinísticos e controladores, baseados na produtividade. Como restaurar a biodiversidade sem expressar esta antropomorfização?

A restauração é definida como a restituição de um ecossistema degradado ao mais próximo possível da sua condição original (BRASIL, 2000). Reis et al. (2003) sugerem que a forma mais adequada para esta restauração é a indução de um processo de sucessão secundária, o mais semelhante possível com os processos naturais, formando comunidades que tendam a uma estabilização no tempo e no espaço. Assim, ações de restauração devem recriar comunidades ecologicamente viáveis, mas protegendo e fomentando a capacidade natural de mudança dos ecossistemas (ENGEL e PARROTA, 2003).

A restauração de comunidades florestais como método científico é recente no Brasil, sendo que no final da década de 70 iniciaram as publicações das primeiras pesquisas de modelos de plantações de árvores nativas (NOGUEIRA, 1977). No final da década de 80 , o modelo vigente no país avançou para uma visão de conservação, primando por valorizar a diversidade de árvores nativas (KAGEYAMA e CASTRO, 1989). Apesar do importante avanço tecnológico, a diversidade foi vista, em geral, como uma meta a ser alcançada em curto prazo (dois a quatro anos), conforme o conceito de tempo humano, apressando a reconstrução de uma floresta através do uso de modelos, onde o número de espécies arbóreas, sua biomassa e densidade foram os únicos parâmetros a serem considerados. Estes projetos basearam-se em um contexto mecanicista, dentro do determinismo cartesiano, agregando em sua quase totalidade, o conceito capitalista de produtividade.

Uma nova tendência de restauradores prima por resgatar modelos de conservação da biofuncionalidade e resgate de interações entre organismos do sistema (REIS et al., 2003, 2010; GÓMEZ-APARICIO et al., 2004; ZAMORA et al., 2004; GRIFFITH e TOY, 2006; METZGER, 2006; HOLL et al., 2010; DURIGAN et al., 2010; CORBIN e HOLL, 2012). Só uma rápida introdução de composição florística não é suficiente para que os processos ecológicos as tornem operantes ao longo 
prazo, sendo necessário compreender e incorporar os processos ecológicos externos à área em restauração (PARKER, 1997). Esta abordagem é contrária aos modelos determinísticos e controladores das plantações arbóreas com distintos grupos ecológicos coetâneos. A nova visão de restauração busca refazer processos naturais e sucessionais, aumentando sua resiliência (PIMM, 1991) através do redirecionamento da comunidade degradada para a sua integração com a paisagem natural que a rodeia, refletindo seus processos estocásticos e sua atual capacidade de campo.

Ganha expressão, neste contexto, a máxima de Grant (1980), quando discute os fluxos gênicos na natureza, deduzindo que os fenômenos eventuais têm maior importância do que os normais. Desta forma, o restaurador não é um ator, mas sim um promotor de eventualidades no sentido de conservar contextos e processos do sistema, concebendo uma "Natureza Participativa".

\section{DESENVOLVIMENTO}

\section{Os ecossistemas naturais}

As comunidades naturais apresentam formas de vida com adaptações distintas quanto à utilização energética conferindo variações na sua estrutura etária e distribuição espacial, em forma de mosaico. Esta heterogeneidade é devido à ação conjunta de fatores abióticos (propriedades físicas e químicas do solo, microtopografia e microclima) e bióticos (produtores, consumidores e decompositores) (REIS et al., 2010). Para Stewart et al. (2002) as distintas fontes de heterogeneidade interagem no sentido de produzir um processo dinâmico de formação de áreas naturais. Rosenzweig (1995) associa a heterogeneidade ambiental com maior probabilidade de ocorrerem nichos ecológicos, enquanto Wilson (2002) registra que há uma significativa correlação entre a heterogeneidade ambiental e a biodiversidade.

Considerando o atual estágio de conhecimento do homem emerge uma indagação: será que se sabe reconstruir uma comunidade natural original? Bascompte et al. (2006), por exemplo, ilustram a complexa teia alimentar de uma comunidade natural de plantas e os seus respectivos dispersores de sementes. Seria pretensioso imaginar que, com nossa engenharia, se saberia restabelecer fielmente ou mesmo aproximar-se de toda uma intricada rede de interações interespecíficas que compõe as comunidades naturais.

Por conseguinte, cabe ao homem promover "gatilhos ecológicos" que disparem e propulsionem a sucessão natural e o potencial de autorregeneração das comunidades. Para isso, é essencial gerar conectância(WILLIAMS e MARTINEZ, 2000)entre os diversos níveis tróficos, oferecendo a essência da vida - alimento, ethos e reprodução - a fim de ocasionar a presença de produtores, consumidores e decompositores, biomassa e recicladores, grãos de pólen e polinizadores, sementes e dispersores. Quanto maior a probabilidade de interações interespecíficas (HURLBERT, 1971) na área em restauração maior será a propulsão da sucessão (REIS e KAGEYAMA, 2003).

Já a diversidade fundada de modo espontâneo é estabelecida com um fluxo gênico associado aos remanescentes vizinhos. Grande parte das áreas rurais no Brasil possui paisagens com vários pequenos remanescentes naturais entremeados numa matriz agrícola, permeável para alguns grupos biológicos. Daí decorre o alto potencial de regeneração natural de muitas fazendas, que geralmente é subestimado pelos empreendedores de projetos de restauração e que, muitas vezes, são encaradas como áreas "sujas" que devem ser previamente "limpas". Por outro lado, é claro que não se deve negligenciar o fato de que muitas áreas degradadas necessitam da intervenção humana para a sua restituição. Mas é preciso frisar que a intervenção humana deve servir apenas para acelerar os processos naturais de autorrenovação, e não, substituir estes pela imposição de um modelo artificial, sob altas taxas de insumos agrícolas. A restituição ambiental através da regeneração natural pode, efetivamente, proporcionar o estabelecimento de alta diversidade de espécies e formas de vida (UHL et al., 1988; GUARIGUATA et al., 1997; TORIOLA et al., 1998; AIDE et al., 2000), compondo uma gama de estratos vegetais em forma de mosaico e conduzindo o sistema, de modo gradativo, para fases sucessionais cada vez mais avançadas. Gatti (2000), numa avaliação da regeneração natural em pastagem no sul do Brasil, registrou após seis anos, 263 espécies distribuídas entre ervas, arbustos, árvores, trepadeiras, epífitas, hemiepífitas, hemiparasitas, palmeiras e pteridófitas.

Em paisagens com poucos remanescentes de vegetação natural, os fragmentos mais próximos às áreas degradadas são as melhores fontes de propágulos para a regeneração, representando núcleos históricos dos fluxos naturais. Nestas áreas, 
em função do mosaico produzido pela paisagem ser bastante heterogêneo, uma complexidade de condições naturais poderá ser potencializada através da incorporação desses núcleos históricos nas áreas a serem restauradas.

\section{Tendências paradigmáticas da restauração de áreas degradadas}

Pickett e Ostfeld (1994) mostram que as principais mudanças que a ciência atravessa, são as mudanças dos seus paradigmas. Esta visão de mundo ou convicção adotada estaria amparada, especialmente, em crenças, valores e técnicas usadas por um determinado método ou disciplina. A ecologia, em especial, tem sofrido várias mudanças paradigmáticas ao longo dos anos, o que forçou mudanças nas técnicas e estratégias de conservação e manejo praticadas. As implicações que decorrem destas mudanças têm marcado a disciplina da ecologia da restauração e sua prática.

A implicação direta que o Paradigma Clássico e seus conceitos têm para a conservação dos recursos naturais está intimamente relacionada com a ideia do "balanço da natureza" (PICKETT e OSTFELD, 1994). Esta teoria considera como sistema ideal aquele conservado e isolado da interferência humana. Desta forma, mesmo com possíveis perturbações, os sistemas se manteriam no balanço, retornando ao estado ideal, próximo ou não da condição inicial, dependendo do atual estádio da paisagem participativa.

Em face deste arquétipo determinístico, tornou-se imediatamente necessário adotar um novo paradigma para a ecologia da restauração (SUDING e HOBBS, 2009; ARONSON, 2010; BRANCALION et al., 2010; DURIGAN et al., 2010; MATTHEWS e SPYREAS, 2010). A crença de que a natureza foi feita para o homem e o homem para governá-la, não só nega a complexidade da dimensão e dinâmica de condições dos sistemas ecológicos, como contraria a ideia da sucessão estocástica, um dos princípios-chave do Paradigma Contemporâneo. Esta teoria é uma metáfora do "fluxo da natureza" e considera que, os sistemas naturais são resultado de uma variedade de fluxos, sendo entendidos como uma soma de processos e contextos. Os processos referem-se às dinâmicas e mecanismos do sistema, enquanto que o contexto refere-se à influência espacial no sistema (PARKER e PICKETT, 1999).

Uma variedade de fluxos pode ser citada: dinâmica da troca de matéria e energia, relações tróficas entre as espécies (produtores, consumidores, decompositores), migração de fenótipos e genótipos, alterações na paisagem (PICKETT e OSTFELD, 1994), processos autogênicos e alogênicos, rede de interações interespecíficas (HURLBERT, 1971), conectância (WILLIAMS e MARTINEZ, 2000), mutualismos entre plantas e animais (BASCOMPTE et al., 2006), entre outros componentes da teia da vida (CAPRA, 1996). Concebendo os sistemas ecológicos sob essa nova perspectiva, entende-se que os modelos utilizados para se fazer restauração devam focar no restabelecimento de uma série de processos e contextos do sistema como um todo, os quais irão gerar uma diversidade de fluxos naturais.

Nesse sentido, as metodologias de restauração devem incorporar esses novos conceitos, baseados em uma variedade de perspectivas e referências, permitindo que a restauração seja parte de um processo dinâmico contínuo.

\section{A nucleação como novo paradigma da restauração ecológica}

O processo de nucleação delineado por Yarranton e Morrison (1974) descreveu a dinâmica espacial da sucessão primária (formação de áreas naturais) em dunas canadenses. Os autores colocaram que, primeiramente, foi formada uma vegetação rala com indivíduos esparsos do arbusto Juniperus spp. (Cupressaceae). Debaixo do microclima proporcionado por estes arbustos, se instalaram núcleos de uma série de espécies herbáceas efêmeras e colonizadoras - Carex sp. (Cyperaceae), Poa sp. (Poaceae) e Smilacina sp. Desf. (Liliaceae), formando uma camada de húmus. Nesta camada rica em matéria orgânica e potássio, esquilos enterravam sementes de Quercus spp. L. (carvalho; Fagaceae), espécie arbórea de grande porte e de final de sucessão, a qual se desenvolvia heterogeneamente, dominando os arbustos de Juniperus spp. e outras plantas colonizadoras, que passaram a ter suas populações reduzidas em núcleos. Nestes núcleos, passaram a se estabelecer muitas outras espécies de final de sucessão, como por exemplo, Prunus sp. (Rosaceae), Shepherdia sp. (Elaegnaceae) e Symphoricarpos sp. (Caprifoliaceae). Portanto, a vegetação de dunas, principiou com um estágio campestre com núcleos esparsos de Juniperus spp. e espécies herbáceas agregadas, passou para um estágio intermediário com o desenvolvimento de núcleos de Quercus spp., os quais, só mais tarde, 
culminaram na formação de florestas longevas de carvalho e seu sub-bosque associado, em áreas mais distantes do mar.

Inspirados na teoria de nucleação de Yarranton e Morrison (1974), ratificada por Franks (2003), Reis et al. $(2003 ; 2010)$ no Brasil, e outros autores internacionais (COLE et al., 2010; HOLL et al., 2010; CALENTANO et al., 2011) simularam a dinâmica espacial da natureza instituindo as técnicas de nucleação. Estas visam formar micro-habitat em núcleos propícios para a abertura de uma série de "eventualidades" para a regeneração natural, como a chegada de espécies vegetais de todas as formas de vida e formação de uma rede de interações entre os organismos. O intuito é promover propulsores ecológicos aumentando a probabilidade de formação de uma diversidade de rotas alternativas de sucessão (FIEDLER et al., 1997), as quais poderão convergir para múltiplos pontos de equilíbrio no espaço e no tempo. Cabe ressaltar que, a geração de mortes (espécies efêmeras) é essencialmente importante neste processo sucessional de abrir espaço para as eventualidades.

Tres e Reis (2007) e Reis et al. (2010) discutem o conceito da nucleação numa perspectiva de restauração da conectividade de paisagens fragmentadas. Os autores consideram a nucleação como um processo envolvendo qualquer elemento, biológico ou abiótico, capaz de propiciar potencialidades para formar, dentro de comunidades em restauração, novas populações através da facilitação e criação de novos nichos de regeneração/colonização e gerando novas situações de conectividade na paisagem. $\mathrm{O}$ resultado da ação destes elementos bióticos e abióticos é a formação de núcleos de diversidade. Neste processo, a nucleação representa uma potencialidade de integração de paisagens fragmentadas, uma vez que gera efeitos locais (em áreas degradadas a restaurar) e efeitos de contexto (em áreas desconectadas pela fragmentação). Os autores ressaltam que para que esse processo nucleador seja efetivo na paisagem e promova conectividade, é imprescindível que os fluxos biológicos se deem nos dois sentidos: entre os "fragmentos-área em restauração" e "área restaurada-paisagem".

Reis et al. (2010) evidenciaram um mecanismo de retroalimentação para ilustrar como se dá o processo nucleador na paisagem. As duas escalas supracitadas podem ser projetadas, uma local e outra de contexto. Primeiramente, considera-se que dentro da paisagem, os fragmentos florestais representam os grandes potenciais de funcionalidade e estocasticidade e podem ser considerados os últimos núcleos de diversidade. A ideia é buscar diversos elementos (solo, micro e macrobiota) dentro destes remanescentes e incorporá-los nas áreas degradadas. A combinação destes elementos representa a criação de uma nova condição na área degradada, a partir da formação de um pequeno e recém-núcleo de diversidade. Com o seu desenvolvimento, tal núcleo tenderia a se irradiar e gerar conectância com as unidades naturais da paisagem (remanescentes de vegetação natural). Esta é a primeira via de conectividade: a conectividade local que se dá entre a área degradada e os fragmentos florestais. Secundariamente, com a sua maturidade, este núcleo formado na área degradada transforma-se num elemento diferenciado, com uma nova diversidade e funcionalidade na paisagem. A partir deste momento este núcleo de floresta madura começa a contribuir com um retorno à paisagem como um feedback produzido (decorrente da própria conectividade entre a área restituída e os fragmentos ao redor). Esta é a segunda via de conectividade: a conectividade de contexto que se dá entre a área restaurada e os fragmentos da paisagem. Neste momento se restaura uma rede de conexões, essencial para promoção da conectividade entre as unidades da paisagem como um todo. A tendência é de que os fluxos biológicos promovidos pela nucleação sejam dinâmicos no tempo e no espaço.

Fundamentada nestas perspectivas locais e de contexto, a restauração através da nucleação, é caracterizada por diversas técnicas que são implantadas, nunca em área total, mas sempre em núcleos, ocupando em torno de $10-30 \%$ da área. Desta forma, a nucleação acelera a sucessão natural permitindo a expressão dos mecanismos de restabelecimento usados pela própria natureza. As diferentes técnicas são implantadas de modo conjugado, e não isoladamente, restituindo a heterogeneidade espacial e temporal.

Cada uma das técnicas de nucleação possui diversos efeitos funcionais e particularidades que, em sinergia, abrangem vários fatores básicos de ecologia para a promoção da sucessão, energia, biodiversidade regional sobre o ambiente degradado e ainda conectividade entre as diferentes unidades da paisagem fragmentada. Quanto maior a diversidade de núcleos, maior será a efetividade das técnicas. Segundo Reis et al. (2003; 2010), Bechara (2006) e Tres e Reis (2007), o conjunto de técnicas de nucleação inclui: 
1) Abrigos artificiais: compostos de pilhas de lenha ou resíduo florestal (proveniente de árvores exóticas eliminadas, podas de árvores urbanas, desmatamentos para mineração e antes da inundação de florestas para hidrelétricas, bem como na limpeza de seus reservatórios artificiais após o alagamento, etc.) que constituem importantes áreas de proteção (SAUVAIN, 2003; BEISEGEL, 2006; DEBELJAK, 2006; MERGANICOVÁ, 2012) para pequenos anfíbios, lagartos, pequenas aves e roedores contra predadores como serpentes, aves de rapina, e contra o próprio aquecimento solar, típico de áreas degradadas. O material orgânico é decomposto por microrganismos e pequenos insetos (EHNSTROM, 2001), que por sua vez, são atraídos pela avifauna. Com o tempo, as pilhas são totalmente decompostas, formando camadas de húmus e restaurando a biota do solo (BAYER e MIELNICZUK, 1999). Quando feito com galhos e caules de maior diâmetro é mais lenta decomposição, a função de abrigar a fauna pode perdurar por muitos anos. Por outro lado, quando se usam galhos e caules de pequeno diâmetro, a sua rápida decomposição acelera a formação de húmus e reconstituição do solo.

2) Coberturas vivas: plantio de espécies rústicas herbáceo-arbustivas (BECHARA et al., 2007a), geralmente de ciclo anual, que florescem e frutificam em poucos meses, atraindo uma série de animais polinizadores, dispersores de sementes e consumidores. Como são plantas de ciclo curto, logo servem de alimento aos decompositores, reciclando a matéria orgânica no solo. Ainda que o uso de espécies nativas seja o ideal, em algumas situações de falta de sementes nativas de ervas e arbustos no mercado, opta-se por determinadas plantas usadas tradicionalmente na adubação verde (BECHARA et al., 2007b), que sejam exóticas, porém, não invasoras e não perenes, saindo naturalmente do ecossistema em pouco tempo (atentando-se sempre para não promover processos de invasão biológica).

3) Transposição de solo: retirada da superfície do solo (topsoil), entre 0 a $10-20 \mathrm{~cm}$ de profundidade mais a serapilheira, de áreas naturais conservadas próximas e o dispondo na área degradada. Facilita o fluxo gênico da biodiversidade regional, através da germinação do banco de sementes e do desenvolvimento da biota do solo. Esta técnica já foi usada por diversos autores através de transposição direta para a área total a ser recuperada (STURGESS e ATKINSON, 1993; RODRIGUES e GANDOLFI, 2000; JAKOVAC, 2007), sendo potencial quando na retirada de solo para mineração ou como no resgate pré-inundação de florestas para a construção de reservatórios artificiais. Porém, Reis et al. (2010) recomendaram o uso desta técnica usando pequenas porções de topsoil, germinadas em bandejas em viveiro florestal, e dispondo as placas de mudas de alta biodiversidade em forma de núcleos na área degradada. Com o uso de pequenas porções de $1 \mathrm{~m}^{2}$ emprestadas das florestas conservadas mais próximas (a serem desmatadas ou não), podese otimizar o tamanho da área a ser recuperada e agenciar a conectividade entre as áreas. Em florestas maduras, estas áreas de empréstimo de banco de sementes, quando pequenas e bem espaçadas, são rapidamente cicatrizadas, não degradando desta maneira a área fonte de sementes.

4) Transposição de chuva de sementes em placas: é feito o plantio de mudas germinadas das sementes que caem, mensalmente, sobre coletores permanentes de sementes de $1 \mathrm{~m}^{2}$ instalados nas comunidades vegetais conservadas mais próximas (a fim de impelir a conectividade entre a área conservada e a área degradada). As sementes, frutos e folhas capturadas são peneirados (abertura de $3,67 \mathrm{~mm}$ ), e em seguida, todo material já triturado é semeado superficialmente em bandejas com substrato em viveiro florestal. Após a emergência das plântulas, as raízes (principalmente de espécies herbáceas) formam uma trama, configurando a placa de mudas (REIS et al., 2010). São produzidas mudas de todas as formas de vida vegetal: lianas, ervas, arbustos, árvores, bromélias e outras epífitas, pteridófitas, etc. A periodicidade de coleta mensal possibilita a implantação no campo de plantas que produzirão frutos ao longo de todos os meses, o que poderá manter os animais de durante todo o ano na área degradada (REIS et al., 1999), considerando-se assim o aspecto fenológico da comunidade reestruturada. Recomenda-se sempre coletar de áreas fonte de sementes bem conservadas e principalmente sem espécies exóticas invasoras, evitando processos de invasão biológica.

5) Poleiros artificiais: estruturas altas (geralmente, quanto mais alto mais efetivas) para o pouso de aves e morcegos, animais que trazem grande quantidade de sementes das áreas naturais remanescentes na região, podendo promover desta forma a conectividade entre as áreas. $\mathrm{O}$ efeito de poleiros já foi detectado por vários autores (McDONNEL e STILES, 1983; GUEVARA et al., 1986; McCLANAHAN e WOLFE, 1993; WHITTAKER e JONES, 1994; HOLL, 1998, 1999; GALINDO-GONZALES et al., 2000; SHIELS e 
WALKER, 2003). Bechara (2007b) recomendou os poleiros do tipo "torre de cipó" de $10 \mathrm{~m}$ de altura, confeccionado com três varas de eucalipto (com a copa) enterradas no solo em forma de cone, nos quais se conduzem trepadeiras como, por exemplo, maracujás nativos (Passifloraceae Juss. ex Roussel) ou cipó-de-são-joão (Pyrostegia venusta Ker (Gawl.) Myers, promovendo desta maneira maior atração de animais, inclusive de morcegos.

6) Plantio de árvores nativas em grupos de Anderson (1953): é feito o plantio não em área total (plantation), mas sim em grupos de cinco a nove mudas altamente adensadas dentro do grupo (sob espaçamento em torno de $1 \times 1 \mathrm{~m}$ ), porém, amplamente espaçados entre grupos na área. Adicionalmente, têm-se utilizado também grupos de mudas de bromélias terrestres, preferencialmente providas de tanque para armazenamento de água e dessedentação da fauna silvestre, bem como para a atração de diversos animais para a área degradada (ROCHA et al., 2000; ZALUAR e SCARANO, 2000; ROCHA et al., 2004; COGLIATTICARVALHO et al., 2010).

7) Trampolins ecológicos com grupos funcionais (sensu REIS et al., 2010): introdução de pequenos refúgios para a fauna dentro da matriz produtiva. No caso de plantios florestais introduzem-se, em continuidade com as fileiras do plantio, núcleos com em torno de 16 mudas de árvores nativas com função facilitadora, a uma distância de um núcleo/ha. A introdução de elementos com funções bem definidas podem provocar mudanças na paisagem, especialmente aumentando a médio e longo prazo a permeabilidade da matriz aos fluxos biológicos, uma vez que tendem a reduzir a distância efetiva de dispersão das espécies, favorecendo a conectividade das unidades da paisagem (REIS e TRES, 2007).

O conjunto de técnicas de nucleação representa um modelo de restauração florestal que contrasta com os métodos determinísticos utilizados, pelo fato de priorizar os processos sucessionais de modo que haja uma menor alteração no rumo da trajetória da sucessão natural. Aparentemente, a nucleação aplicada é mais lenta para atingir uma vegetação arbórea que corresponda ao clima tropical predominante no Brasil, mas representa uma base para a formação de comunidades vegetacionais que possam futuramente atuar como novos núcleos funcionais dentro da atual paisagem fragmentada.

\section{CONSIDERAÇÕES FINAIS}

A humanidade se sentiu, por muito tempo, dona dos recursos disponíveis do pequeno planeta Terra e, até, com direitos de criar uma nova realidade, motivada pela ciência moderna (BOFF, 2000 ; 2007) que sugeriu negar a legitimidade de outras formas de pathos e diálogo com a natureza, como a sua observação e interpretação. $\mathrm{O}$ crescimento científico e comercial da Era Moderna nos séculos XVII e XVIII resultou num grande antropocentrismo onde $\mathrm{o}$ homem recebeu a incumbência de dominar a natureza e até aperfeiçoála. Dentro desta concepção, a diversidade natural e suas variações deveriam ser substituídas pela perfeição geométrica (SALATINO, 2001), tal como aquela adotada pelos plantios convencionais de recuperação, onde um modelo pré-estabelecido de natureza foi imposto.

Uma nova tendência de modelos de restauração vem primando por abordagens mais amplas e integradas, buscando uma visão sistêmica da paisagem. A proposta do modelo de nucleação é biocêntrica: contrária à visão pontual e $r$ educionista da natureza, prioriza refazer processos naturais da sucessão estocástica, direcionando a comunidade para a sua integração com a paisagem que a rodeia.

Ações nucleadoras representam um avanço em modelos de restauração, expressando o forte caráter ético com a conservação e manejo das paisagens. Os núcleos formados mostram que pequenas interferências a nível local e de contexto, representam "gatilhos ecológicos" promotores de conectividade e de integração das áreas naturais e produtivas.

\section{AGRADECIMENTOS}

Ao Conselho Nacional de Desenvolvimento Científico e Tecnológico - CNPq - Brasil.

\section{REFERÊNCIAS BIBLIOGRÁFICAS}

AIDE, T. M. et al. Forest regeneration in a chronosequence of tropical abandoned pastures: implications for restoration ecology. Restoration Ecology, Malden, v. 8, n. 4, p. 328-338, Dec. 2000. ANDERSON, M. L. Spaced-Group planting. Unasylva, Roma, v. 7, n. 2, p. 1-15, June 1953. ARONSON, J. What can and should be legalized in ecological restoration? Revista Árvore, Viçosa, 
v. 34, n. 3, p. 451-454, maio/jun. 2010.

BASCOMPTE, J. et al. Asymetric coevolutionary networks facilitate biodiversity maintenance. Science, New York, v. 312, n. 5772, p. 431-433, Apr. 2006.

BAYER, B.; MIELNICZUK, J. Dinâmica e função da matéria orgânica. In: SANTOS, J. A.; CAMARGO, F. A. O. (Eds). Fundamentos de Matéria Orgânica no Solo: ecossistemas tropicais e subtropicais. Porto Alegre: Gênesis, 1999. p. 10-25.

BECHARA, F. C. Unidades demonstrativas de restauração ecológica através de técnicas nucleadoras: Floresta Estacional Semidecidual, Cerrado e Restinga. 2006. 248 f. Tese (Doutorado em Recursos Florestais) - Universidade de São Paulo, Piracicaba, 2006.

BECHARA, F. C. et al. Quebra de dormência de sementes de Chamaecrista flexuosa (L.) Greene Leguminosae visando a restauração ecológica do cerrado. Revista de Biologia Neotropical, v. 4, n. 1, p. 58-63, 2007a.

BECHARA, F. C. et al. Unidades demonstrativas de restauração ecológica através de técnicas nucleadoras de biodiversidade. Revista Brasileira de Biociências, Porto Alegre, v. 5, n. 1, p. 9-11, jul. 2007b.

BEISIEGEL, B. M. Shelter availability and use by mammals and birds in an Atlantic forest area. Biota Neotropica, Campinas, v. 6, n. 1, p. 1-16, 2006.

BOFF, L. 2007. La era ecocida. Disponível em: <http://www.miradaglobal. c o m/ i n d e x.ph p o p t i o n $=\mathrm{com}$ content $\&$ view $=$ article $\&$ id $=333 \% 3$ Ala-era-ecoci $\mathrm{da} \&$ catid $=31 \% 3$ Atemas $\&$ Itemid $=35 \&$ lang $=p t>$. Acesso em: 2 de fevereiro de 2011.

BOFF, L. Saber cuidar: ética do humano compaixão pela terra. Petrópolis: Vozes, 2000. $197 \mathrm{p}$.

BRANCALION P. H. S. et al. Instrumentos legais podem contribuir para a restauração de florestas tropicais biodiversas. Revista Árvore, Viçosa, v. 34, n. 3, p. 455-470, maio/jun. 2010.

BRASIL. Ministério do Meio Ambiente. Lei $\mathrm{n}^{0}$ 9985, de 18 de julho de 2000 . Institui o Sistema Nacional de Unidades de Conservação da Natureza. Brasília, DF, 18 jul. 2000. Disponível em: <http://www.mma. gov.br/port/conama/ legiabre.cfm?codlegi $=322>$ Acesso em: 2 de fevereiro de 2011.

CALENTANO, D. et al. Litterfall dynamics under different tropical forest restoration strategies in Costa Rica. Biotropica, Malden, v. 43, n. 3, p. 279-287, May 2011.

CAPRA, F. A teia da vida. New York: Anchor Books, 1996. 265 p.

COGLIATTI-CARVALHO, L. et al. Volume de água armazenado no tanque de bromélias, em restingas da costa brasileira. Acta Botânica Brasileira, Feira de Santana, v. 24, n. 1, p. 84-95, 2010.

COLE, R. J. et al. Seed rain under tree islands planted to restore degraded lands in a tropical agricultural landscape. Ecological Applications, Washington, v. 20, n. 5, p. 1255-1269, July 2010.

DANSEREAU, P. Ecological impact and human ecology. In: DARLING, F.; MILTON, J. P. (Eds). Future environments of North America. New York: Natural History Press, 1966. p. 425-462.

DEBELJAK, M. Coarse woody debris in virgin and managed forest. Ecological Indicators, Kiel, v. 6, n. 4, p. 733-742, Nov. 2006.

DURIGAN, G. et al. Normas jurídicas para a restauração ecológica: uma barreira a mais a dificultar o êxito das iniciativas? Revista Árvore, Viçosa, v. 34, n. 3, p. 471-485, maio/jun. 2010.

ENGEL, V. L.; PARROTA, J. A. Definindo a Restauração Ecológica: Tendências e Perspectivas Mundiais. In: KAGEYAMA, P. Y.; OLIVEIRA, R. E.; MORAES, L. F. D.; ENGEL, V. L.; GANDARA, F. B. (Eds). Restauração Ecológica de Ecossistemas Naturais. Botucatu: FEPAF, 2003. p. 1-26.

FIEDLER, P. L. et al. The paradigm shift in ecology and its implications for conservation. In: PICKETT, S. T. A.; OSTFELD, R. S; SHACHAK, M. (Eds). The Ecological Basis of Conservation: heterogeneity, ecosystems and biodiversity. New York: International Thomson Publishing, 1997. p. 83-92.

FRANKS, S. J. Facilitation in multiple life-history stages: evidence for nucleated succession in coastal dunes. Plant Ecology, Netherlands, v. 168, n. 1, p. 1-11, Aug. 2003.

GALINDO-GONZALES, J. et al. Bat and bird generated seed rains at isolated trees in pastures in a tropical rainforest. Conservation Biology, Boston, v. 14, n. 6, p. 1693-1703, Dec. 2000.

GATTI, G. A. Composição florística e estrutura da vegetação de uma área em recuperação ambiental, Guaraqueçaba-PR. 2000. 113 f. Dissertação (Mestrado) - Universidade Federal do 
Paraná, Curitiba, 2003.

GÓMEZ-APARICIO, L. et al. Applying plant facilitation to forest restoration: a metaanalysis of the use of shrubs as nurse plants. Ecological Applications, Washington, v. 14, n. 4, p. 1128-1138, Aug. 2004.

GRANT, V. Gene flow and the homogeneity of species populations. Biologisches Zentralblatt, v. 99, p. 157-169, 1980.

GRIFFITH, J. J.; TOY, T. J. O modelo físicosocial da recuperação ambiental. Brasil Mineral, São Paulo, v. 22, n. 242, p. 166-174, fev. 2006.

GUARIGUATA, M. R. et al. Structure and floristics of secondary and old-growth forest stands in lowland Costa Rica. Plant Ecology, Netherlands, v. 132, n. 1, p. 107-120, Aug. 1997.

GUEVARA, S. et al. The role of remnant forest trees in tropical secondary succession. Vegetatio, Netherlands, v. 66, n. 2, p. 77-84, May 1986.

HOLL, K. D. Do bird perching structures elevate seed rain and seedling establishment in abandoned tropical pasture? Restoration Ecology, Malden, v. 6, n. 3, p. 253-261, Sept. 1998.

HOLL, K. D. Factors limiting tropical rain forest regeneration in abandoned pasture: seed rain, seed germination, microclimate, and soil. Biotropica, Washington, v. 31, n. 2, p. 229-242, June 1999.

HOLL, K. D. et al. Planting seedlings in tree islands versus plantations as a large-scale tropical forest restoration strategy. Restoration Ecology, Malden, v. 19, n. 4, p. 470-479, June 2010.

HURLBERT, S. The nonconcept of species diversity: a critic and alternative parameters. Ecology, Tempe, v. 52, n. 4, p. 577-586, July 1971. JAKOVAC, A. C. C. O uso do banco de sementes florestal contido no topsoil como estratégia de recuperação de áreas degradadas. 2007. 150 f. Dissertação (Mestrado em Biologia Vegetal) - Universidade Estadual de Campinas, Campinas, 2007.

KAGEYAMA, P. Y.; CASTRO, C. F. A. Sucessão secundária, estrutura genética e plantações de espécies arbóreas nativas. IPEF, Piracicaba, n.41/42, p.83-93, jan./dez. 1989.

MATTHEWS, J. W.; SPYREAS, G. Convergence and divergence in plant community trajectories as a framework for monitoring wetland restoration progress. Journal of Applied Ecology, London, v. 47, n. 5, p. 1128-1136, Oct. 2010.

McClANAHAN, T. R.; WOLFE, R. W.
Accelerating forest succession in a fragmented landscape: the role of birds and perches. Conservation Biology, Boston, v. 7, n. 2, p. 279-287, June 1993.

McDONNEL, M. J.; STILES, S. W. The structural complexity of old field vegetation and the recruitment of bird-dispersed plant species. Oecologia, Berlin, v. 56, n. 1, p. 109-116, 1983. MERGANICOVÁ, K. et al. Deadwood in forest ecosystems. In: BLANCO, J. A.; LO, Y. H. (Eds). Forest Ecosystems - more than just trees. Rijeka: InTech, 2012. p. 81-108.

METZGER, J. P. How to deal with non-obvious rules for biodiversity conservation in fragmented landscapes? Natureza e Conservação, Curitiba, v. 4, n. 2, p. 125-137, out. 2006.

NIETZSCHE, F. W. A filosofia na idade trágica dos gregos. Rio de Janeiro: Lisboa Ed., 1995. $107 \mathrm{p}$.

OST, F. A natureza à margem da Lei: a ecologia à prova do direito. Lisboa: Instituto Piaget, 1995. $400 \mathrm{p}$.

NOGUEIRA, P. Reflorestamento heterogêneo com essências indígenas. Boletim Técnico do Instituto Florestal, São Paulo, n. 24, p. 1-71, 1977.

PARKER, V. T. The scale of successional models and restoration objectives. Restoration Ecology, Malden, v. 5, n. 4, p. 301-306, Dec. 1997.

PARKER, T. V.; PICKETT, S. T. A. Restoration as an ecosystem process: implications of the modern ecological paradigm. In: URBANSKA, K.; WEBB, N.; EDWARD, P. (Eds). Restoration Ecology and Sustainable Development. Cambridge: University Press, 1999. p. 17-32.

PICKETT, S. T. A.; OSTFELD, R. S. The shifiting paradigm in ecology. In: KNIGHT, R. L., BATES, S. F. (Eds). A New Century for Natural Resources Management. Washington: Island Press, 1994. p. 261-278.

PIMM, S. L. The balance of nature: ecological issues in the conservation of species and communities. Chicago: The University of Chicago Press, 1991. 434 p.

REIS, A. et al. Restoration of damaged land areas: using nucleation to improve successional processes.

Natureza \& Conservação, Curitiba, v. 1, n. 1, p. 85-92, abr. 2003.

REIS, A. et al. Nucleation in tropical ecological restoration. Scientia Agricola, Piracicaba, v. 67, n.2, p. 244-250, mar./abr. 2010. 
REIS, A.; KAGEYAMA, P. Y. Restauração de áreas degradadas utilizando interações interespecíficas. In: KAGEYAMA, P. Y.; OLIVEIRA, R. E.; MORAES, L. F. D.; ENGEL, V. L.; GANDARA, F. B. (Eds). Restauração Ecológica de Ecossistemas Naturais. Botucatu: FEPAF, 2003. p. 91-110.

REIS, A. et al. Recuperação de áreas florestais degradadas utilizando a sucessão e as interações planta-animal. Série Cadernos da Biosfera, São Paulo, n. 14, p. 1-42, 1999.

REIS, A.; TRES, D. R. Nucleação: integração das comunidades naturais com a paisagem. In: FUNDAÇÃO CARGILL (Coord.). Manejo Ambiental e Restauração de Áreas Degradadas. São Paulo: Cargill, 2007. p. 28-55.

ROCHA, C. F. D. et al. Bromeliads: Biodiversity amplifiers. Journal of Bromeliad Society, Orlando, v. 50, n. 2, p. 81-83, 2000.

ROCHA, C. F. D. et al. Conservando uma larga porção da diversidade biológica através da conservação de Bromeliaceae. Vidalia, Viçosa, v. 2, n. 1, p. 52-72, 2004.

RODRIGUES, R. R.; GANDOLFI, S. Conceitos, tendências e ações para a recuperação de florestas ciliares. In: RODRIGUES, R. R.; LEITÃO FILHO, H. F. (Ed). Matas Ciliares: Conservação e Recuperação. São Paulo: FAPESP, 2000. p. 241-243.

ROSENZWEIG, M. L. Species diversity in space and time. Cambridge: University Press, 1995. $423 \mathrm{p}$.

SALATINO, A. Nós e as plantas: ontem e hoje. Revista Brasileira de Botânica, São Paulo, v. 24, n. 4, p. 483-490, dez. 2001.

SAUVAIN, R. B. Dead wood in managed forests: how much and how much is enough? Development of a snag quantification method by remote sensing \& GIS and snag targets based on three-toed woodpeckers' habitat requirements. 2003. 184 f. Tese (Doutorado) - École Polytechnique Fédérale de Lausanne, Lausanne, 2003.

SHIELS, A. B.; WALKER, L.R. Bird perches increase forest seeds on Puerto Rican landslides.

Restoration Ecology, Malden, v. 11, n. 4, p. 457-465, Dec. 2003.

STEWART, A. J. A. et al. The world is heterogeneous: ecological consequences of living in a patchy environment. In: HUTCHINGS, M. J., JOHN, E. A., STEWART, A. J. A. (Eds). The Ecological Consequences of Environmental
Heterogeneity. Cambridge: University Press. 2002, p. 1-8.

STURGESS, P.; ATKINSON, D. The clear-felling of sand-dune plantations: soil and vegetational processes in habitat restoration. Biological Conservation, London, v. 66, n. 3, p. 171-183, June 1993.

SUDING, K. N.; HOBBS, R. J. Threshold models in restoration and conservation: a developing framework. Trends in Ecology \& Evolution, Amsterdam, v. 24, n. 5, p. 271-279, March 2009.

TORIOLA, D. et al. Distribution of primary forest plant species in a 19-year old secondary forest in French Guiana. Journal of Tropical Ecology, Cambridge, v. 14, n. 3, p. 323-340, May 1998.

TRES, D. R.; REIS, A. La nucleación como propuesta para la restauración de la conectividad del paisaje. In: SEMINÁRIO INTERNACIONAL DE RESTAURACIÓN ECOLÓGICA, 2., 2007, Santa Clara. Anais... Santa Clara: Grupo Cubano de Restauración Ecológica, 2007. p. 1-11.

UHL, C. et al. Abandoned pastures in Eastern Amazônia. I. Patterns of plant succession. Journal of Ecology, Oxford, v. 76, n. 3, p. 663-681, Sept. 1988.

WHITTAKER, R. J.; JONES, S. H. The role of frugivorous bats and birds in the rebuilding of a tropical forest ecosystem, Krakatau, Indonesia. Journal of Biogeography, Oxford, v. 21, n. 3, p. 245-258, May 1994.

WILLIAMS, R.; MARTINEZ, N. Simple rules yield complex food webs. Nature, London, v. 404, n. 6774, p. 180-183, March 2000.

WILSON, S. D. Heterogeneity, diversity and scale in plant communities. In: HUTCHINGS, M. J.; JOHN, E. A.; STEWART, A. J. A. (Eds). The Ecological Consequences of Environmental Heterogeneity. Cambridge: University Press, 2002. p. 52-69.

YARRANTON, G. A.; MORRISON, R. G. Spatial dynamics of a primary succession: nucleation. Journal of Ecology, Oxford, v. 62, n. 2, p. 417428, July 1974.

ZALUAR, H. L. T.; SCARANO, F. R. Facilitação em restingas de moitas: um século de buscas por espécies focais. In: ESTEVES, F. A.; LACERDA, L. D. (Eds). Ecologia de Restingas e Lagoas Costeiras. Rio de Janeiro: NUPEM/UFRJ, 2000. p. 3-23. 
ZAMORA, R. et al. Las interacciones planta- Ecología del Bosque Mediterráneo en un planta y planta-animal en el contexto de la Mundo Cambiante. Madrid: EGRAF, 2004. p. sucesión ecológica. In: VALLADARES, F. (Ed). 371-393. 